\title{
Physician Activities During Time Out of the Examination Room
}

\author{
Valerie Gilchrist, $M D^{1}$ \\ Gary McCord, $M A^{1}$ \\ Susan Labuda Schrop, MS ${ }^{1}$ \\ Bridget D. King, $M D^{2}$ \\ Kenelm F. McCormick, $M D^{3}$ \\ Allison M. Oprandi, MD \\ Brian A. Selius, DO \\ Michael Cowber, $M D^{6}$ \\ Rishi Mabeshwary, $M D^{6}$ \\ Falguni Patel, $M D^{7}$ \\ Ami Shab, $M D^{8}$ \\ Bonny Tsai, MD \\ Mia Zabarna, $M D^{10}$ \\ 'Northeastern Ohio Universities College of \\ Medicine (NEOUCOM), Rootstown, Ohio \\ ${ }^{2}$ Akron General Medical Center, Akron, Ohio \\ ${ }^{3}$ Barberton Citizens Hospital, Barberton, Ohio \\ ${ }^{4}$ Aultman Hospital, Canton, Ohio \\ ${ }^{5}$ St Elizabeth's Hospital, Youngstown, Ohio \\ ${ }^{6}$ Allegheny General Hospital, Pittsburgh, Pa \\ ${ }^{7}$ Cleveland Clinic Foundation, \\ Cleveland, Ohio \\ ${ }^{8}$ Rush Presbyterian St Luke's Medical Center, \\ Chicago, Ill \\ ${ }^{9}$ Ohio State University Children's Hospital, \\ Columbus, Ohio \\ ${ }^{10}$ Boston University School of Public Health, \\ Boston, Mass

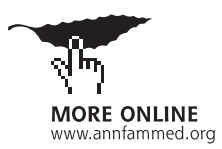

Conflicts of interest: none reported

\section{CORRESPONDING AUTHOR}

Valerie Gilchrist, MD

Department of Family Medicine

Brody School of Medicine

at East Carolina University

600 Moye Blvd - Brody 4N84

Greenville, NC 27834

gilchristv@mail.ecu.edu

\begin{abstract}
PURPOSE Comprehensive medical care requires direct physician-patient contact, other office-based medical activities, and medical care outside of the office. This study was a systematic investigation of family physician office-based activities outside of the examination room.
\end{abstract}

METHODS In the summer of 2000, 6 medical students directly observed and recorded the office-based activities of 27 northeastern Ohio community-based family physicians during 1 practice day. A checklist was used to record physician activity every 20 seconds outside of the examination room. Observation excluded medical care provided at other sites. Physicians were also asked to estimate how they spent their time on average and on the observed day.

RESULTS The average office day was 8 hours 8 minutes. On average, 20.1 patients were seen and physicians spent 17.5 minutes per patient in direct contact time. Office-based time outside of the examination room averaged 3 hours 8 minutes or $39 \%$ of the office practice day; $61 \%$ of that time was spent in activities related to medical care. Charting (32.9 minutes per day) and dictating (23.4 minutes per day) were the most common medical activities. Physicians overestimated the time they spent in direct patient care and medical activities. None of the participating practices had electronic medical records.

CONCLUSIONS If office-based, medically related activities were averaged over the number of patients seen in the office that day, the average office visit time per patient would increase by 7 minutes (40\%). Care delivery extends beyond direct patient contact. Models of health care delivery need to recognize this component of care.

Ann Fam Med 2005;3:494-499. DOI: 10.1370/afm.391.

\section{INTRODUCTION}

ime has become a precious commodity for primary care physicians. Patients and physicians both are frustrated by what they perceive as inadequate patient contact time. ${ }^{1-6} \mathrm{An}$ important question is, "How do physicians spend their time?" Understanding how time is spent is crucial to the economic viability and future success of the new model practice proposed by the Future of Family Medicine report. ${ }^{7,8}$

A number of published studies have described the content of patient visits. ${ }^{9 \cdot 14}$ Stange et a ${ }^{14}$ used direct observation, the most accurate method for studying physician activities, ${ }_{1}^{15}$ to describe the complexity of a physician-patient primary care office visit. Outside of the examination room, physicians perform many undocumented responsibilities and activities, including but not limited to charting, dictating, reviewing reports, consulting medical resources, consulting colleagues, and communicating with patients. These activities have a direct bearing not only on patient well-being and outcomes, but also on physicians' abilities to manage their practices. In an Ecuadorian study of physician time use, Bratt et a $\mathrm{l}^{15}$ found that $40 \%$ of office time was spent outside of direct patient contact, and that nearly one half of this time was spent on activities integrally related in 
some way to medical care. The present study is a systematic investigation of community-based physicians' office-based activities outside of the examination room.

\section{METHODS}

A working group of physicians in northeastern Ohio who participated in the Direct Observation of Primary Care Study ${ }^{14}$ observed that documentation of out-ofexamination room activities was needed to understand the true nature and scope of activities and responsibilities within a practice. As a result, a checklist to record activities occurring outside the examination room was developed. Residency faculty from the Northeastern Ohio Universities College of Medicine's (NEOUCOM) Department of Family Medicine reviewed and revised the checklist. The final checklist consisted of separate medical and nonmedical categories for the following activities: reading and writing; telephone calls; conversations with nurses, staff, and physicians; and conversations with patients or patients' families. Additional medical categories included charting and dictating. Additional nonmedical care categories included reading and responding to mail $;$ teaching students, residents, nurses, and staff; time in committees and meetings; time with sales representatives; and time in personal activities. An "other" category for both medical and nonmedical activities was also included. Medical activities were defined as patient care activities related to patients present as well as those not present. We did not differentiate between these 2 situations. The checklist is included in Supplemental Appendix 1, available online-only at http://www.annfammed. org/cgi/content/full/3/6/494/DC1.

Using the checklist, 6 medical student research assistants were trained to identify and record physician activities based on the direct observation technique. ${ }^{14}$ During observation, research assistants wore cassette players attached to their belts or held in the pocket of a laboratory coat. Through earpieces, the research assistants heard beeps programmed at 20-second intervals on prerecorded 90-minute cassette tapes. They then identified and recorded the physician's activity for that moment when the physician was out of the examination room. If a single activity was occurring during the beep, observers marked an $\mathrm{X}$ in the bubble of the appropriate category on the checklist. If 2 activities were occurring simultaneously, such as talking on the telephone while eating lunch, observers marked a / in both of the appropriate categories.

Before the study began, the research assistants piloted the study procedures working in pairs with physician research directors during the director's officebased hours. Questions and problems that arose were noted and later discussed during a debriefing session with all of the research assistants to eliminate any confusion concerning how to appropriately identify and record physician activities. For example, physician conversation with the research assistant was counted as teaching if the content centered around medical care and was counted as research if the content concerned the ongoing study. Physicians walking from one examination room to another was counted as part of direct patient contact and was not noted on the checklist. Activities observed that were not listed on the checklist were written in the "other" category. Some medically related examples were finding drug samples for patients and performing microscopic examinations.

Study participants were 30 community-based family physicians in northeastern Ohio. Participants were recruited using the annually updated departmental database of the NEOUCOM Department of Family Medicine. We searched this database for physicians who indicated an interest in research participation. Approximately 100 physicians expressed interest in participating in research at the time of this study. Physician interest in the study was followed up by personal communication from the faculty research directors of Family Medicine's Office of Research. Participants were selected based on the need to have representation of physicians across all 3 of our major consortium communities; in addition, participants had to have an officebased community practice and had to be willing to be shadowed during a representative, normal, full-length workday. Qualified physicians were asked to choose 4 or 5 days when they were scheduled to be in the office all day. The Office of Research set up physician participation schedules based on this information.

Each trained observer shadowed 5 physicians for 1 full day during a 2 -week period at the end of June 2000. The total number of patients that physicians saw each day was logged. Activities were recorded from the time the physician arrived at the office until the time the physician left the office for the day. If the physician had to leave the office but was planning to return, the time leaving and returning to the office, as well as the reason for leaving, were recorded. This time was excluded from the study, and observers did not accompany physicians. Patient care activities occurring before arriving at the office and after leaving the office were also not included in this study.

To compare perceived with actual time spent on various activities, at the end of the day physicians were asked to complete a questionnaire estimating the percentage of time they spent in direct patient contact, chart work and dictating, reading and writing, telephone calls, conversations, teaching, committees and meetings, and other activities. Physicians estimated 
times for the study day as well as for an average workday. This questionnaire is included in Supplemental

Appendix 2, available online-only at http://www. annfammed.org/cgi/content/full/3/6/494/DC1.

The principal outcome measure for this study was the amount of time physicians spent in each outof-examination room activity as recorded during direct observation. Each X on the checklist was counted as 20 seconds of total time in the appropriate category, and each / contributed 10 seconds. The time inside the examination room was calculated by subtracting the out-of-examination room time and time the physician left the office from the length of the total office day. Secondary outcome measures were the physicians' estimates of time spent in out-of-examination room activities, the difference between perceived and actual time spent, and whether time spent doing the activities was related to physician sex, type of practice, patient payer status, and number of years in practice. The NEOUCOM Institutional Review Board reviewed and approved the study protocol.

\section{RESULTS}

Twenty-seven physicians participated from 22 practices. Of the 30 physicians originally recruited, 3 were eliminated because observers were not able to shadow these physicians for an entire workday. There were 18 participating physicians from 13 group practices, 8 solo physicians, and 1 physician from a health maintenance organization. Of the 27 physicians who completed the study, 26 had a hospital affiliation and 19 were College of Medicine clinical faculty. Fifteen physicians practiced in a suburban setting, 11 were from urban settings, and 1 was from a rural setting. The mean physician age was 42 years $(\mathrm{SD}=9.2$ years, range $=$ 29-69 years). Nineteen were men and 8 were women. Twenty-six of 27 were residency trained.

Averaging across all practices, the most common payer status was capitated managed care $(38 \%$, SD $=24.5 \%$, median $=40 \%$ ), followed by commercial $(31.3 \%, \mathrm{SD}=25.1 \%$, median $=23 \%)$, Medicare $(18.3 \%, \mathrm{SD}=18.3 \%$, median $=20 \%)$, self-pay $(6.2 \%$, $\mathrm{SD}=6.3 \%$, median $=5 \%)$, Medicaid $(5.8 \%, \mathrm{SD}=$ $10.9 \%$, median $=4 \%)$, and other $(0.5 \%, \mathrm{SD}=1.5 \%$, median $=0 \%)$. These statistics represent the composition of the practices themselves, not necessarily the composition of patients attending the clinics when physicians were observed. No individual patient data were collected. There was considerable insurance variation across sites. The percentage for managed care ranged from $0 \%$ to $80 \%$; for commercial, from $5 \%$ to $100 \%$; for Medicare, from $0 \%$ to $40 \%$; for Medicaid, from $0 \%$ to $50 \%$; and for self-pay, from $0 \%$ to $25 \%$. Compared with membership of the American Academy of Family Physicians, ${ }^{16}$ our sample had fewer group practices and female physicians, and the participating practices had fewer patients covered by Medicaid, more physicians working with a managed care payer status, and more commercially insured patients. None of the participating practices had electronic medical records.

The average length of the office-based workday was 8 hours 8 minutes (mean $=488.4$ minutes, $\mathrm{SD}=$ 88.2 minutes, median $=505$ minutes, range $=280-625$ minutes). Nearly $40 \%$ of total time, 3 hours 8 minutes (mean $=188.7$ minutes, $\mathrm{SD}=59.0$ minutes, median $=183$ minutes, range $=54-297.2$ minutes), was spent outside of the examination room. On average, physicians saw 20.1 patients $(\mathrm{SD}=7.2$, median $=21$, range $=2-36)$ per day and spent 17.5 minutes $(\mathrm{SD}=7.4 \mathrm{~min}$ utes, median $=15$ minutes, range $=8.2-37.6$ minutes $)$ per patient inside the examination room. During the day observed, 3 physicians left the office and returned, 2 for hospital rounds and 1 for a private meeting. The average time out of the office for these 3 physicians was 55 minutes and was not recorded as part of the office day. No record was kept of any work done before arriving at the office or after leaving the office.

There were no times when 3 or more activities cooccurred. Table 1 displays activities observed, the average and median number of minutes of observation for each activity, and the total percentage of time spent in the office for each activity. As indicated by the size of the standard deviations, there was considerable physician variability for each of these activities; therefore, medians are also presented. Additionally, the percentage each activity contributed to the medically or nonmedically related categories is presented. Medically related activities accounted for 114.2 minutes (23\% of total office-based time and $61 \%$ of total out-of-examination room time). Medically related out-of-examination room time averaged over the number of patients seen increased the average time spent per patient by 7 minutes ( $\mathrm{SD}=8.0$ minutes). The most common medically related activities were charting, dictating, and medical reading and writing. The most common nonmedically related activities were personal activities, meetings with sales representatives, and nonmedical conversations with nurses or staff.

Using linear regression, we tested whether the number of physician practice years was related to time spent with each activity recorded. The only significant finding was that with each additional year of practice, the amount of time spent in committees or in meetings with staff increased by approximately 30 seconds ( $\mathrm{F}=$ 20.92, $\left.P<.001, R^{2}=0.456\right)$. There were no significant differences in the way time was spent comparing physicians by sex and type of practice (group vs solo). There 


\begin{tabular}{|c|c|c|c|c|}
\hline Activity & $\begin{array}{c}\text { Minutes per Day } \\
\text { Mean } \pm \text { SD } \\
\text { (Median) }\end{array}$ & $\begin{array}{c}\text { Medical Time Out } \\
\text { of Examination Room } \\
\%\end{array}$ & $\begin{array}{c}\text { Nonmedical Time Out } \\
\text { of Examination Room } \\
\%\end{array}$ & $\begin{array}{c}\text { Total Time } \\
\text { in Office } \\
\%\end{array}$ \\
\hline \multicolumn{5}{|l|}{ Medical documentation } \\
\hline Charting & $\begin{array}{c}32.9 \pm 28.0 \\
(24)\end{array}$ & 28.8 & - & 6.7 \\
\hline Dictating & $\begin{array}{c}23.4 \pm 19.2 \\
(25)\end{array}$ & 20.5 & - & 4.8 \\
\hline \multicolumn{5}{|l|}{ Medical activities } \\
\hline Medical reading and writing & $\begin{array}{c}18.5 \pm 14.8 \\
(13)\end{array}$ & 16.2 & - & 3.8 \\
\hline $\begin{array}{l}\text { Medical conversations with } \\
\text { nurse/staff }\end{array}$ & $\begin{array}{l}16.1 \pm 8.0 \\
\quad(14)\end{array}$ & 14.1 & - & 3.3 \\
\hline Medical telephone calls & $\begin{array}{c}15.0 \pm 13.2 \\
(11)\end{array}$ & 13.1 & - & 3.1 \\
\hline $\begin{array}{l}\text { Medical conversations with } \\
\text { physicians }\end{array}$ & $\begin{array}{c}2.9 \pm 3.9 \\
(1)\end{array}$ & 2.5 & - & 0.6 \\
\hline $\begin{array}{l}\text { Medical conversations with } \\
\text { patient or patient's family }\end{array}$ & $\begin{array}{c}2.6 \pm 2.6 \\
(2)\end{array}$ & 2.3 & - & 0.5 \\
\hline $\begin{array}{l}\text { Finding or distributing } \\
\text { drug samples to patients }\end{array}$ & $\begin{array}{c}1.6 \pm 3.9 \\
(0)\end{array}$ & 1.4 & - & 0.3 \\
\hline Laboratory work & $\begin{array}{c}1.1 \pm 4.1 \\
(0)\end{array}$ & 1.1 & - & 0.2 \\
\hline \multicolumn{5}{|l|}{ Nonmedical activities } \\
\hline Personal activities & $\begin{array}{c}30.4 \pm 30.4 \\
(22)\end{array}$ & - & 39.7 & 6.2 \\
\hline Sales representative meetings & $8.5 \pm 12.6$ & - & 11.1 & 1.7 \\
\hline $\begin{array}{l}\text { Nonmedical conversations } \\
\text { with nurse/staff }\end{array}$ & $\begin{array}{c}7.5 \pm 7.7 \\
(5)\end{array}$ & - & 9.8 & 1.5 \\
\hline Nonmedical telephone calls & $3.3 \pm 4.5$ & - & 4.3 & 0.7 \\
\hline $\begin{array}{l}\text { Nonmedical conversations } \\
\text { with physicians }\end{array}$ & $\begin{array}{c}3.0 \pm 5.7 \\
(0)\end{array}$ & - & 3.9 & 0.6 \\
\hline Teaching & $\begin{array}{c}4.8 \pm 6.2 \\
(2)\end{array}$ & - & 6.3 & 1.0 \\
\hline Mail & $\begin{array}{c}4.6 \pm 7.2 \\
(2)\end{array}$ & - & 6.0 & 0.9 \\
\hline Staff meetings & $\begin{array}{c}2.2 \pm 11.5 \\
(0)\end{array}$ & - & 2.9 & 0.5 \\
\hline \multirow[t]{2}{*}{ Other nonmedical* } & $12.1 \pm 18.7$ & - & 15.8 & 2.5 \\
\hline & & $\begin{array}{c}\text { Minutes per Day } \\
\text { Mean } \pm \text { SD }\end{array}$ & $\begin{array}{c}\text { Minutes per Day } \\
\text { Mean } \pm \text { SD }\end{array}$ & \\
\hline \multicolumn{5}{|l|}{ Overall time in office } \\
\hline Out of examination room & $\begin{array}{c}188.7 \pm 59.0 \\
(183)\end{array}$ & $114.2 \pm 47.4$ & $76.5 \pm 45.1$ & 39 \\
\hline Inside examination room & $\begin{array}{c}299.7 \pm 81.9 \\
(303)\end{array}$ & $299.7 \pm 81.9$ & - & 61 \\
\hline Total & $\begin{array}{c}488.4 \pm 88.2 \\
(505)\end{array}$ & - & - & 100 \\
\hline
\end{tabular}

were significant positive correlations between percentage of Medicaid payer status and nonmedical reading and writing time $(r=0.87, P<.001)$ and personal time $(r=0.85, P<.001)$.

Table 2 compares physician estimates with actual time spent. The sample means for the physician estimates were larger for all categories, with the exception of committees/meetings and other activities. Paired comparison $t$ tests showed that physicians significantly overestimated the amount of time they spent in direct 


\begin{tabular}{|c|c|c|c|c|}
\hline Activity & $\begin{array}{l}\text { Actual Time } \\
\text { Minutes* }\end{array}$ & $\begin{array}{c}\text { Physician- } \\
\text { Estimated Time } \\
\text { Minutes* }\end{array}$ & $t$ & $P$ Value \\
\hline Direct patient care & 300 & 330 & 2.12 & .045 \\
\hline Charts and dictating & 56.4 & 84.6 & 2.92 & .008 \\
\hline Reading and writing & 19.9 & 24.6 & 0.72 & .48 \\
\hline Telephone calls & 18.4 & 26.0 & 1.97 & .06 \\
\hline Conversations & 33.5 & 37.2 & 0.69 & .497 \\
\hline Teaching & 4.8 & 9.5 & 1.14 & .27 \\
\hline Committees and meetings & 10.7 & 3.5 & -2.47 & .02 \\
\hline Other & 47.0 & 20.6 & -4.21 & $<.001$ \\
\hline
\end{tabular}

sales representative meetings, which may have involved some medically related activities.

In this study, the average number of patients seen per day was 20.1, which is consistent with findings of previous research using direct obsevation. ${ }^{14}$ This study focused only on the time the physician was in the office. The average office-based practice day of 8 hours 8 minutes excludes the time spent delivering medical care at other sites, such as hospitals, nursing homes, emergency departments, or homes.

patient contact $(t=2.12, P=.045)$ and in charting and dictating $(t=2.92, P=.008)$.

\section{DISCUSSION}

Previous research on family physician office visits revealed the complexity of these visits by focusing on what transpired during face-to-face encounters between physicians and patients. ${ }^{14}$ In contrast, using the same methods, this study examined medical care that is delivered inside the physicians' office but outside of face-to-face physician-patient contact. Each of 27 family physicians was observed during 1 full-length day in their office. Sixty percent of office-based time was spent in direct patient contact. Twenty-three percent of office-based time was spent in medical activities conducted outside of the examination room.

These results are consistent with those obtained by Bratt et al. ${ }^{15}$ Out-of-examination room medical care activities, averaged over the number of patients seen in the office that day, would increase the time spent on each patient encountered by approximately 7 minutes (from 17 to 24 minutes, approximately) or 2 hours a day in medical care provided by the physician. The total time spent on medical care is $40 \%$ more than the length of the office visit inside of the examination room, and this time does not include additional, considerable responsibilities that physicians perform outside of the office. This time is not judged to be fairly compensated in a fee-for-service payment model and is only indirectly considered in a capitation model. This additional time is, however, consistent with increasing complexity of primary care management. ${ }^{1,3,6}$ We suspect that patients are typically unaware of this time spent on their behalf. This study also did not consider medical care delivered by other members of the office-based health care team. Our estimates of medically related time use are likely conservative because we excluded mail, teaching, and
The average length of visit for the physicians in our study was 17.5 minutes. This corresponds well with physician self-reported visit duration from the National Ambulatory Medical Care Survey (NAMCS) as reported by Blumenthal et $\mathrm{al}^{17}$ in 1991-1992 (16.3 minutes), Gilchrist et $\mathrm{al}^{13}$ in 1991-1992 (16.0 minutes), and Mechanic et $\mathrm{al}^{18}$ in 1989-1998 (18.3 minutes). Stange et al, ${ }^{14}$ however, found with direct observation that the average visit duration was 10 minutes (data collected 1994-1995). The longer visit duration reported in the NAMCS has been attributed to physician overestimation because of the self-report methods, although the NAMCS instructs physicians to record visit duration as face-to-face contact. In our study, physicians overestimated the time they spent both in direct patient contact and in medically related activities. This finding is consistent with memory models of time perception that suggest the duration of a remembered event is directly proportional to the complexity of material and changes experienced. ${ }^{19}$ Participants may also have been influenced by the social acceptability of spending time doing "work." This study took place in the summer of 2000. One interpretation of our results is that physicians overestimate the time spent in medically related activities, but also that the complexity of time spent has increased.

The limitations of this study include the self-selection of physician participants. All physicians were from the northeastern Ohio area, and physicians chose a group of days for possible observation. There were more board-certified physicians, fewer female physicians, and fewer group practices compared with the American Academy of Family Physicians membership. ${ }^{16}$ Even though research assistants were rigorously trained using the same criteria, it is possible that there were variations in how they recorded physician activity. Although the Hawthorne effect is always a concern with a study using direct observation, physicians were instructed to continue with their usual office day and knew of no 
hypothesis guiding the observation. The time estimate was requested at the end of the study day. The trained observers reported the observation task as easy. The participating physicians reported that the observation did not disrupt their office practice. Finally, only observable activity could be recorded.

None of the participating practices used an electronic health record. Future investigation might examine the effects of electronic medical records on time use and thus the financial impact of this investment in a practice. Our interpretation of the result that physicians with more years in practice engaged in more meetings with staff is that they probably have assumed practice leadership roles. It may be, however, that they use and relate to their staff differently. These interpretations and reflections bear further investigation. Further examination of the nature of personal activities in the office may also reveal means to improve efficiency.

Family physicians spend $23 \%$ of their office-based time providing medical care outside of the traditional face-to-face office visit. In our study, this averaged 7 more minutes per patient. This care is largely unrecognized by patients and payers. Physicians are reimbursed for direct patient contact in a fee-for-service model, not for patient outcomes. ${ }^{5}$ To provide patients a medical home, work in teams, manage information on the patient's behalf, and engage in asynchronous communication, all of which are called for in the Future of Family Medicine report, ${ }^{7}$ the industrial "piecework" model of medical care must be replaced. "The current reimbursement system for primary care practices is not sustainable," according to Spann. ${ }^{8}$ This study of time is but a small example of the inadequacy of our current model. Medical care planning, policy, and reimbursement must reflect physicians' and other health care professionals' work to support a contextually flavored, continuity-based, evolving partnership between patients and physicians that will be necessary to sustain satisfaction and quality for both health care professionals and patients. ${ }^{4,8,20-23}$

To read or post commentaries in response to this article, see it online at http://www.annfammed.org/cgi/content/full/3/6/494.

Key words: Physician time; direct observation; health care delivery; reimbursement

Submitted February 24, 2005; submitted, revised, June 21, 2005; accepted July 11, 2005.

The following versions of this report were presented previously: McCord G, Gilchrist VJ. Physician activities during time out of the examination room. 34th Annual Society of Teachers of Family Medicine Spring Conference, Denver, Colo, April-May 2001; Cowher M, Maheshwary R, Patel F, Shah A, Tsai B, Zaharna M. Physician activities during time out of the examination room [poster]. Ohio Academy of Family Physicians 19th Annual Research Day, Columbus, Ohio, 2000.

\section{References}

1. Kassirer JP. Doctor discontent. N Engl J Med. 1998;339:1543-1545.

2. Fischman J. Who will take care of you? US News World Rep. 2005; 138:44-46.

3. Mechanic D. Physician discontent: challenges and opportunities. JAMA. 2003;290:941-946.

4. Morrison I, Smith R. Hamster health care. BMJ. 2000;321:1541-1542.

5. Morrison I. The future of physician's time. Ann Intern Med. 2000;132:80-84.

6. Center for Studying Health System Change. So much to do, so little time: physician capacity constraints 1997-2001. 2003. Available at: http://www.hschange.com/index.cgi. Accessed February 14, 2005.

7. The Future of Family Medicine Project Leadership Committee. The future of family medicine: a collaborative project of the family medicine community. Ann Fam Med. 2004;2(Suppl 1):S3-S32.

8. Spann SJ. Report on financing the new model of family medicine. Ann Fam Med. 2004;2(Suppl 3):S1-S21.

9. Marsland DW, Wood M, Mayo F. A data bank for patient care, curriculum, and research in family practice: 526,196 patient problems. J Fam Pract. 1976;3:25-28.

10. Marsland DW, Wood M, Mayo F. Content of family practice. Part I: rank order of diagnoses by frequency. Part II: diagnoses by disease category and age/sex distribution. J Fam Pract. 1976;3:37-68.

11. Rosenblatt RA, Cherkin DC, Schneeweiss R, et al. The structure and content of family practice: current status and future trends. J Fam Pract. 1982;15:681-722.

12. Rosenblatt RA, Hart LG, Gamliel S, Goldstein B, McClendon BJ. Identifying primary care disciplines by analyzing the diagnostic content of ambulatory care. J Am Board Fam Pract. 1995;8:34-45.

13. Gilchrist V, Miller RS, Gillanders WR, et al. Does family practice at residency teaching sites reflect community practice? J Fam Pract. 1993;37:555-563.

14. Stange KC, Zyzanski SJ, Jaen CR, et al. Illuminating the "black box": a description of 4454 patient visits to 138 family physicians. J Fam Pract. 1998;46:377-389.

15. Bratt JH, Foreit J, Chen PL, et al. A comparison of four approaches for measuring clinician time use. Health Policy Plan. 1999;14:374-381.

16. American Academy of Family Physicians. 2005 Facts About Family Medicine. 2005. Available at: http://www.aafp.org/x530.xml. Accessed February 21, 2005.

17. Blumenthal D, Causino N, Chang YC, et al. The duration of ambulatory visits to physicians. J Fam Pract. 1999;48:264-271

18. Mechanic D, McAlpine DD, Rosenthal M. Are patients' office visits with physicians getting shorter? N Engl J Med. 2001;344:198-204.

19. Francis-Smythe JA, Robertson IT. On the relationship between time management and time estimation. Br J Psychol. 1999;90:333-347.

20. Poplin C. Productivity in primary care: work smarter, not harder. Arch Intern Med. 2000;160:1231-1233.

21. Showstack J, Rothman AA, Hassmiller SB. The Future of Primary Care. San Francisco, Calif: Jossey-Bass; 2004.

22. Grumbach K, Bodenheimer T. Reconstructing primary care for the twenty-first century. In: Isaacs SL, Knickman JR, eds. Generalist Medicine and the United States Health System: The Robert Wood Johnson Foundation Series on Health Policy. San Francisco, Calif: Jossey-Bass; 2004:48-73.

23. Larson EB. General internal medicine at the crossroads of prosperity and despair. In: Isaacs SL, Knickman JR, eds. Generalist Medicine and the United States Health System: The Robert Wood Johnson Foundation Series on Health Policy. San Francisco, Calif: Jossey-Bass; 2004:138144. 